\title{
"Outros" coletivos femininos: Lutas e Resistências que formam mulheres quilombolas na Amazônia
}

\author{
"Other" female collectives: Struggles and Resistances \\ that form quilombola women in the Amazon
}

\author{
Colectivos femeninos "otros": luchas y resistencias \\ que forman mujeres quilombolas en la Amazonía
}

ELLEN RODRIGUES DA SILVA MIRANDA (iD ${ }^{a}$

DORIEDSON DO SOCORRO RODRIGUES (iD $\mathrm{b}$

\section{Resumo}

Analisamos, neste artigo, a relação entre trabalho e processos formativos de mulheres quilombolas ao resistirem às ações do Capital, no contexto da Comunidade Quilombola Tambaí-Açu - Mocajuba/PA, Amazônia. Para tanto, à luz do materialismo histórico dialético, consideramos entrevistas semiestruturadas com quatro mulheres e três homens. Assim, ao se fazer análise de conteúdo, entendemos que monocultivos introduzidos na Amazônia, como o da pimenta do reino, têm transformado o trabalho-cultura das comunidades tradicionais, a partir dos interesses do capital. Entretanto, contraditoriamente, as mulheres quilombolas, nos trabalhos dos mutirões, têm sido resistentes às ações mercadológicas. Nossas análises evidenciam, ainda, que os coletivos femininos das mulheres quilombolas estão inseridos no campo do debate de gênero, raça, patriarcado e classe, pois, a seus modos, suas lutas e resistências, no cotidiano dos quilombos, constituem-se como "outras" formas de lutas ao capital e fazem parte dos processos formativos das classes sociais, revelando-se como lutas sociais

a Universidade Federal do Pará, Belém, PA, Brasil. Mestra em Educação e Cultura, e-mail: ellenrodrigues.slp@gmail.com

b Universidade Federal do Pará, Belém, PA, Brasil. Doutor em Educação, e-mail: doriedson@ufpa.br 
distintas de "outros" coletivos femininos, defendendo-se, no cotidiano de suas comunidades, o direito a ter direito, à terra, ao trabalho, educação, saúde; enfim, lutam pelo direito de produzir a vida, a partir de uma perspectiva histórica que toma os interesses de classe trabalhadora enquanto ser social quilombola, mas com amplitude para a vida em comum, quer de homens como de mulheres.

Palavras-chave: Mulheres quilombolas. Lutas-Resistências. Capitalismo. Formação.

\begin{abstract}
In this article, we analyze the relationship between labor and training processes of quilombola women when they resist the actions of Capital, in the context of the Tambaí-Açu Quilombola Community - Mocajuba / PA, Amazon. Therefore, in the light of historical dialectical materialism, we considered semi-structured interviews with four women and three men. Thus, when doing content analysis, we understand that monocultures introduced in the Amazon, such as black pepper, have transformed the labor-culture of traditional communities, based on the interests of capital. However, contradictorily, quilombola women, in the work of the joint efforts, have been resistant to market actions. Our analyzes also show that the female collectives of quilombola women are inserted in the field of the debate of gender, race, patriarchy and class, because, in their ways, their struggles and resistance, in the daily life of quilombos, constitute themselves as "other" forms of struggles against capital and are part of the training processes of social classes, revealing themselves as social struggles distinct from feminine collective "others", defending, in the daily lives of their communities, the right to have the right, to land, to labor, education, health; finally, they fight for the right to produce life, from a historical perspective that takes the interests of the working class as a quilombola social being, but with scope for life in common, both for men and women.
\end{abstract}

Keywords: Quilombola women. Resistance-fights. Capitalism. Formation.

\title{
Resumen
}

En este artículo, analizamos la relación entre el trabajo y los procesos de formación de las mujeres quilombolas cuando se resisten a las acciones del Capital, en el contexto de la Comunidad Quilombola Tambaí-Açu - Mocajuba / PA, Amazonía. Por tanto, a la luz del materialismo dialéctico histórico, consideramos entrevistas semiestructuradas con cuatro mujeres y tres hombres. Así, al hacer análisis de contenido, entendemos que los monocultivos introducidos en la Amazonía, como la pimienta negra, han transformado la cultura laboral de las comunidades tradicionales, en base a los intereses del capital. Sin embargo, contradictoriamente, las mujeres quilombolas, en el trabajo de los esfuerzos conjuntos, se han resistido a las acciones del mercado. Nuestros análisis también muestran que los colectivos femeninos de mujeres quilombolas se insertan en el campo del debate de género, raza, patriarcado y clase, porque, a su manera, sus luchas y resistencias, en la vida cotidiana de los quilombos, se constituyen en "otros". 
formas de luchas contra el capital y son parte de los procesos de formación de las clases sociales, revelándose como luchas sociales distintas de los colectivos femeninos "otros", defendiendo, en el día a día de sus comunidades, el derecho a tener derecho, a la tierra, al trabajo, educación, salud; finalmente, luchan por el derecho a producir la vida, desde una perspectiva histórica que toma los intereses de la clase trabajadora como ser social quilombola, pero con espacios de vida en común, tanto para hombres como para mujeres.

Palabras clave: Mujeres quilombolas. Luchas de resistencia. Capitalismo. Formación.

\section{Introdução}

Ao tratar da relação trabalho e processos formativos de lutas-resistências de mulheres quilombolas em oposição ao capital, no contexto da Comunidade Quilombola Tambaí-Açu1, Estado do Pará, Amazônia, alguns achados de pesquisa de mestrado realizada de 2017 a 2019, pautada na perspectiva do materialismo histórico dialético, têm possibilitado a compreensão de que as mulheres e os homens se constroem historicamente à medida que transformam a natureza em favor de suas necessidades, partindo-se do pressuposto de "não há um mundo humano fora da história e que não nascemos humanos, nos tornamos humanos em sociedade, em comunidade[...]" (FRIGOTTO; CIAVATTA; CALDART, 2020, p. 14). Dessa maneira, ao se produzirem necessidades nesta transformação do seu meio, transformam a si mesmos, suas identidades, como ato educativo do trabalho ${ }^{2}$, de formação e autoformação.

Trata-se, assim, de uma perspectiva de análise que toma os sujeitos, homens e mulheres, como históricos, produtores de materialidades, mas que ganha uma complexidade em termos acadêmicos quando se articula ao método marxiano o estudo do gênero "feminino", uma vez que algumas vertentes do marxismo se

\footnotetext{
${ }^{1}$ Comunidade tradicional, município de Mocajuba/PA, titulada em 2009 pelo Instituto de Terras do Pará (ITERPA), reconhecida pela Fundação Palmares em 2012, possui população de 757 (setecentos e cinquenta e sete) pessoas, sendo 363 (trezentos e sessenta e três) mulheres e 394 (trezentos e noventa e quatro) homens, totalizando 190 (cento e noventa) famílias.

${ }^{2}$ Compreendido, aqui, conforme Frigotto, Ciavatta e Ramos (2005), como produtor de valores de uso para manter e reproduzir a vida; dessa forma, é crucial e educativo, mesmo quando se dá sob a negatividade das relações de classe existentes no capitalismo, que também não são naturais, mas obra dos seres humanos.
} 
distanciaram da pauta raça-gênero por diversos motivos, dentre os quais, embora não avancemos nessa discussão, dada a objetividade deste trabalho, a necessidade de se entender a ação do capital contra a humanidade de forma geral, não se atentando para as especificidades do diverso dessa humanidade. Entretanto, discutir as categorias gênero - mulher e raça, a partir da realidade concreta vivenciada com as mediações de segunda ordem do capital, em que há, conforme Frigotto (2010), a intensificação das forças de trabalho para suprir às necessidades do mercado, torna-se uma tarefa necessária, diante das lutas-resistências ao capital. É neste viés de entendimento que esta exposição procurou se situar.

Isto posto, destacamos que nosso objetivo neste trabalho foi analisar a relação trabalho e processos formativos de mulheres quilombolas ao resistirem às ações do Capital na Amazônia, no interior de atividades produtivas. Para tanto, compreende-se, conforme Bogo (2010), que a categoria "resistência" se configura como uma constante (re)construção de luta pela sobrevivência e (re)afirmação histórica. Além de resistirem, (re)constroem, em meio às contradições do processo, a permanência da comunidade que, dialeticamente, vem tentando ultrapassar os limites do status quo (do sistema capital), por meio do que entendemos, de acordo com Pistrack (2018), como autogestão do trabalho que destoa do trabalho individualizado, constituindo-se trabalho festivo que une forças e é materializado no saber do trabalho quilombola: os mutirões, que atuam em favor da organização da comunidade, conforme os sujeitos (mulheres e homens) salientam em seus relatos.

Diante dessas considerações e como forma de contribuição ao debate, aprofundamos, nesta exposição, análise sobre mulheres quilombolas e [re]construção das identidades na contradição trabalho-capital, destacando que, ao considerar as "mulheradas quilombolas" no debate sobre gênero, raça, patriarcado, classe, buscamos responder, a partir das entrevistas com quatro mulheres e três homens $^{3}$, como as mulheres do campo, negras-quilombolas, lutam e resistem às

\footnotetext{
${ }^{3}$ Ressalte-se que, na totalidade da pesquisa, contamos com nove quilombolas (quatro mulheres e cinco homens). Mas, para esta exposição, consideramos entrevistas semiestruturadas (TRIVIÑOS, 1987) com quatro mulheres e três homens, analisadas pelo conteúdo (BARDIN, 1977).
} 
reproduções ampliadas do capital, construindo processos que formam "outros" coletivos femininos.

Nessa direção, consideramos que os estudos que têm encaminhado debates sobre mulheres negras, a partir das categorias raça e classe, entendem que uma não anula a outra; ou seja, conforme Ângela Davis (1977), a gente precisa refletir bastante para perceber as "intersecções" entre raça, classe e gênero. Nesse campo de reflexão, outras autoras também nos ajudam compreender que o racismo é uma ideologia da exploração capitalista e concretamente a mulher-negra é a mais explorada (GONZÁLEZ, 1984).

De forma a ampliar ainda mais esta compreensão e assim não cairmos, segundo Cisne (2015), na segmentação positivista, Saffioti (2004, p. 125) nos faz pensar que este processo é permeado de contradições "fundidas e enoveladas ou enlaçadas em um nó" de um "novelo - patriarcado-racismo-capitalismo historicamente constituído"; logo, "as relações sociais de sexo, raça e classe são ‘consubstanciais' e 'coextensivas"' (CISNE, 2015, p. 83), ou seja, não podemos falar da construção de outro mundo, para além do capital, sem considerar as diversas lutas das mulheres.

No campo das lutas contra a opressão capitalista, precisamos compreender que os "feminismos" ou coletivos "femininos" não são iguais, isto é, são diversos (ARRUZZA; BHATTACHARYA; FRASER, 2018). Ao tratar da nossa realidade amazônica, entendem-se por lutas "femininas" também as lutas das trabalhadoras em outros "chãos", para além das cidades e fábricas, aí devendo-se entender também as lutas presentes no campo, como as das mulheres negras-quilombolas. Lutas cotidianas, que compõem, no dizer de González (1988), as "amefricanidade[s]".

Desta forma, pontua-se que, no antagonismo de classes produzido pelo capital, as relações sociais envolvem "[...] materialidades de corpos reais, que possuem sexo/sexualidade, raça/etnia [...]" (CISNE, 2018, p 233), já que, para além dos "feminismos" de negras urbanas, com suas lutas e resistências legitimas ao capital, também há lutas quilombolas do campo, que também, a seus modos, lutam e resistem ao capital. 
Nessa direção, as evidências têm revelado que há "outras" lutas em outros "chãos" além das cidades e fábricas. Embora ainda seja um campo ínfimo em termos de pesquisas na Amazônia, autoras como Pinto (2004, 2010) apresentam estudos de mulheres negras rurais, que contribuem para que suas comunidades resistam até o tempo histórico-presente, nas dimensões de cultura e poder político, enquanto raça e gênero.

Isto posto, destacamos que a presente exposição está estruturada em duas seções que se articulam. Na primeira, trouxemos à tona alguns elementos sobre a constituição do ser social quilombola em contradição com o capital, os monocultivos e as resistências dos mutirões às ações mercadológicas.

$\mathrm{Na}$ segunda, analisamos, teórico-empiricamente, as mulheres quilombolas como luta-resistência ao capital, pois compreendemos que as tentativas do racionalismo do capital, de homogeneizar as heterogenias, não têm obtido êxito em sua totalidade. Tem-se tentado construir uma história de invisibilidade no que diz respeito ao trabalho das mulheres. Às mulheres, tem sido condicionada historicamente a negação de seu papel, enquanto trabalhadoras e, quando se trata de mulheres negras/quilombolas, então, essa invisibilidade ganha tons mais intensos, ao tentar torná-las “desaparecidas” dos processos da vida real.

Finalmente, nas considerações, delineamos o entendimento de que estes processos são a própria luta entre classes, cuja base está nas materialidades produtivas da existência na contradição Trabalho-Capital. Portanto, nestes termos, luta-se para que as transformações ocorram no campo econômico, da cultura e dos valores.

\section{Ações do Capital na Amazônia e as lutas-resistências- quilombolas dos mutirões}

Para início de análise, faz-se necessário registrar, mesmo que sinteticamente, alguns elementos do processo histórico que arrancou o povo negro da África para ser escravizado no Brasil. Assim, teoricamente, entendemos que as Comunidades Quilombolas são resultantes de histórico processo de luta pela liberdade e contra a opressão, principalmente quando consideramos que a expansão do capitalismo pós-mercantilismo (séc. XV) transformou o Atlântico em rota do tráfico negreiro, 
permitindo com que milhares de seres humanos fossem retirados de seus territórios de origem, à força, para maximizarem a acumulação e concentração inerentes ao modo de produção capitalista. Nas viagens, muitos homens e mulheres negros/as morreram. Nas colônias europeias, os que sobreviveram foram submetidos a intensas atrocidades, continuamente violentados, manipulados, açoitados, obrigados a trabalhar para o capital, conforme Freitas (1982), Genovese (1976) e Gomes (2003).

Estudos e estimativas de Fonseca (2011) revelam que, aproximadamente, mais de três milhões e quinhentos mil negros/negras tenham sido trazidos durante este período para o Brasil. Deste número, de acordo com Salles (1988), foram destinados ao Pará, aproximadamente, 53.217 escravizados africanos. Os Portugueses, no período colonial, imprimiram nas páginas da História do Brasil a vergonhosa liderança escravista e, com ela, um verdadeiro etnocídio.

No entanto, esse processo não se deu de forma passiva. As negras e os negros que chegaram vivos no Brasil construíram uma história de luta e resistência contra a escravidão a que foram submetidos. De várias formas se opuseram a isso, como por meio de suicídios, negando-se a trabalhar, organizando rebeliões, fugindo, construindo quilombos, lutando pela liberdade. Com isso, os conflitos e fugas em busca por liberdade foram cruciais para a construção de quilombos, o que permite entender as negras e os negros como verdadeiros guerreiros da "liberdade" (FUNES, 2012).

No Pará, os mocambos, assim como em outras regiões do Brasil, foram alvo de muitas ações coercitivas do Estado nos séculos XVIII e XIX. Inúmeros conflitos ocorreram e muitas negras e negros foram mortos. Porém, “os quilombos podiam ser destruídos, os quilombolas não. Com a mesma qualidade os mocambos nasciam e renasciam com o mesmo ideal em outros cantos das matas" (FUNES, 2012, p. 557).

Mulheres e homens negros encontraram muitos obstáculos nas matas, contudo, a partir do trabalho, transformaram a natureza em prol da sua sobrevivência ao se alimentarem e se curarem por meio de frutos, folhas, raízes, cipós e plantas, fazendo roçados, produzindo, comercializando o excedente. Tornaram a região sua aliada, construindo, dessa forma, quilombos com cultura baseada nos ensinamentos da floresta e dos indígenas, (re)criando saberes, como os mutirões quilombolas, que lhes deram condição de resistência. Típicos quilombolas 
com especificidades que somente podem ser encontradas na Amazônia e que se mantêm em comunidade até os dias atuais.

As resistências dos quilombos, a partir dos mutirões, de acordo com Pinto (2001; 2004; 2007), têm se dado pela organização e afirmação cultural configurada em rituais, danças, ritmos e cantorias, que reafirmam continuamente as suas lutasresistências, inclusive em seus movimentos sociais. Suas formas de organização têm se mostrado cada vez mais necessárias, já que convivem com contínuas tentativas de aniquilamento tanto material como simbólico, por parte do capitalismo, desde suas origens.

Diante deste contexto, contudo, o capital tem se materializado, modificado as comunidades tradicionais de diversas formas, com diversas faces; e, dentre essas, através de monocultivos, que se intensificam na região amazônica, desde o período militar no Brasil (1964-1984). Esses empreendimentos agrícolas, incentivados pelo governo, vieram e têm se mantido na Amazônia, através de políticas de financiamentos públicos, a partir da década de 1970.

A fim de suprir as necessidades do mercado mundial, essa lógica tem favorecido produções de commodities, para serem, conforme Caldart (2012, p. 136), "transacionados unicamente no mercado e representa historicamente a integração das economias e sociedades periféricas à divisão do trabalho no sistema capitalista internacional”, tais como: pimenta-do-reino, dendê, açaí-irrigado, milho, soja, dentre outros. Resquícios do colonialismo concreto, que aprofundam ainda mais a posição periférica, dependente e subordinada dos países da América Latina em relação ao mundo do capital (TRUJILLO, 2020).

Como se nota, a Amazônia vem sendo atravessada pelo capital de diversas formas e, na experiência das relações de trabalho que produz, leva os/as trabalhadores/as a personificar o que nos revelaram as/os quilombolas do TambaíAçu de "trabalho pro outro", de forma a se conscientizar da diferença entre o trabalho da roça e o trabalho dos pimentais, que atende, este último, aos interesses do capital. Nos pimentais, implantados nos arredores da Comunidade Quilombola do Tambaí-Açu, a partir da década de 1970, algumas e alguns quilombolas foram "seduzidos/as" ideologicamente ao trabalho assalariado. Entretanto, com o passar do tempo, como nos disse a quilombola E. N. C. (62 anos, entrevista, 2), "nós 
apercebemo" explorados e voltamos ao trabalho que aprendemos como os nossos pais, isto é, aos mutirões, também chamados de "cunvidados" ou:

Putirum, simboliza a união de várias pessoas como uma única e grande família que indistintamente associava trabalho e lazer. Estes se processavam da seguinte forma: a "companhia" convocava os habitantes do povoado para executar uma determinada tarefa do roçado, por exemplo, o plantio que era mais comum, marcava-se o dia deste. Na noite anterior ao "cunvidado" acontecia o encontro dos participantes, que "desinibidos" com alguns goles de cachaça promoviam o Sambade-cacete [e banguê] (PINTO, 2004, p. 97).

Percebe-se assim que, embora o objetivo do mutirão seja comum entre outras comunidades tradicionais, no sentido de unir forças para diminuir o dispêndio do trabalho como forma de cooperatividade e trabalho ontocriativo, também produz valores cruciais para vida de comunidades quilombolas da Amazônia Paraense, bem como de outras comunidades tradicionais e regiões do Brasil. Conhecida inclusive como muxirum, essa experiência do trabalho, assim como outras culturas, "não se reaparece da mesma forma” (THOMPSON, 1998, p. 303), diferenciando-se nas definições dos rituais que a compõem. Assim, nas relações que permeiam economia-cultura,

Mulheres e homens das classes populares sofrem (e produzem) diferentes formas de dominação e discriminação. São as mulheres, no entanto, que se constituem, predominantemente, no pólo subordinado na histórica relação assimétrica entre os gêneros masculino e feminino. Vêm, entretanto, lutando e se afirmando como seres de seu tempo, no próprio enfrentamento dos limites colocados à sua humanização. Nesse movimento vão criando e recriando modos de ser, de dar sentido às suas vidas e de produzir saberes. (FISCHER; ZIEBELL, 2005, p. 1)

A mulher e o homem quilombola, à medida que ganham consciência de si, percebem, através do ato educativo dos mutirões, que é este que os humaniza, ou seja, não é o trabalho estranhado, configurado no escravismo e nas diversas formas do modo de produção capitalista, como ainda experiencia a comunidade Quilombola do Tambaí-Açu ao vivenciarem (nem todos) os pimentais da região no entorno à comunidade, bem como outras formas e faces da lógica capitalista. 


\section{Mulheres Quilombolas: “Outras” lutas e resistências ao Capital}

A construção histórica do capitalismo revela que sempre precisou da mão de obra das mulheres e suas crianças, que, exploradas, sempre foram menos remuneradas em relação aos homens. Para a sociedade de mercado, as mulheres nada mais são que instrumentos de produção (MARX; ENGELS, 2005).

Deste modo, nos monocultivos, como o da pimenta-do-reino, implantada na Amazônia paraense, a partir da década de 1930, pelos imigrantes japoneses, com intuito de suprir necessidades do mercado, não foi e não é diferente. As mulheres foram e ainda são recrutadas para esta forma de trabalho; muitas das quais são mulheres negras-quilombolas. E nessa experiência, acabam também levando suas crianças. As mulheres são vistas pelos patrões como melhor mão de obra para colheita e capina, pois o trabalho é considerado como se precisasse de mais delicadeza no trato e menor remuneração. Esses elementos foram coletados nas falas tanto das mulheres quanto dos homens.

Buscou-se, assim, fazer uma análise deste achado, pois, em relação às mulheres, tem sido construída uma história de invisibilidade no que diz respeito ao trabalho. Às mulheres, tem sido condicionada historicamente a negação de seu papel, enquanto trabalhadoras e, quando se trata de mulheres negras, então, essa invisibilidade ganha tons mais intensos, ao tentar torná-las "desaparecidas" dos processos da vida real. Outrossim, de acordo com Cisne (2015, p. 37), "Há, portanto, uma nítida hierarquia que revela desigualdades no interior de uma mesma classe. Tal hierarquia da estrutura da desigualdade social segue a seguinte ordem: homens brancos, mulheres brancas, homens negros (e pardos) e mulheres negras". E acrescentamos: mulheres quilombolas.

Nos pimentais implantados e intensificados a partir da década de 1970, na Região do Baixo Tocantins/PA, dentre os municípios que a compõem ${ }^{4}$, o município de Mocajuba, região Vale do Tambaí-Açu, teve muitos homens e mulheres

\footnotetext{
${ }^{4}$ Situada no Estado do Pará, Região Norte, é composta por 11 municípios: Abaetetuba, Acará, Baião, Barcarena, Cametá, Igarapé-Miri, Limoeiro do Ajuru, Mocajuba, Moju, Oeiras do Pará e Tailândia.
} 
recrutados. Havia, no período da colheita, uma eminente imigração de trabalhadores e trabalhadoras de outros municípios, que se instalavam com suas famílias até finalizar a colheita. Esta dinâmica de trabalho ainda ocorre nos dias atuais.

Esse processo de recrutamento ao trabalho dos pimentais também se deu na Comunidade Quilombola Tambaí-Açu, onde algumas mulheres e homens se arriscavam mata a dentro, em caminhada, rumo aos pimentais implantados pelos arredores, como nos disse a quilombola E. N. C. (62 anos, entrevista 2): "nós saía daqui quatro horas da manhã, eu saía de casa. Eu saía junto com os pessoá [...]. A mulherada e a gente ia embora pra lá. A gente ia andando por tudo aí, e ia saí lá [...]" nos pimentais dos japoneses.

A quilombola E. N. C. (Entrevista 2) vivenciou o trabalho nos pimentais e nos fala com apropriação de como o dedicar-se ao trabalho dos patrões, influenciada pelo salário, mudou a dinâmica da sua vida e da comunidade. Assim, no seu dizer, com a entrada dos pimentais na região, "mudou eu com a minha roça", ou seja, o monocultivo intensivo da pimenta-do-reino, implantado nos arredores da comunidade, mudou, segundo R. S. N. (44 anos, entrevista 4), a "forma do mutirão" e com este mudou o eu, mudou a roça, mudou a comunidade.

Essa mudança, objeto de percepção das trabalhadoras, parte da perspectiva de que os mutirões, nas vozes das "mulheradas", tanto para aquelas que foram, quanto para aquelas que não foram trabalhar nos pimentais, têm o significado de produção da comunidade, diferente da produção dos pimentais, que se destinam ao patrão. Nesse sentido, para a quilombola T. C. (87 anos, entrevista 8), que faz questão de dizer "nunca trabalhei em pimentá":

Os cunvidados (mutirões) era pra derribar, roçar, plantar. Fazia os cunvidados grandes. Plantavam, juntava muita gente, porque naquele tempo o povo era animado. Os velhos de hoje, eram novos, e as criançadas tavam tudo pequeno. E naquele tempo, [...] no tempo do nosso pai, eles faziam o banguê, já tinha o banguê, o samba né? O trabalho era animado [...]. (Entrevista 8)

O dizer da quilombola T. C. é revelador de como o "trabalho animado", festivo, movimentava a comunidade, reunia, mobilizava; e, assim como trabalho que educa numa perspectiva emancipadora, construiu a consciência da união de forças 
para diminuir o trabalho pesado, aumentar a produção e dar condição de sobrevivência a todos.

Dessa forma, mesmo tendo experienciado o que chamou de "trabalho pro outro", a quilombola E. N. C. também traduz o mutirão como:

muita brincadeira, quando chegavam na casa pela tarde, era muita brincadeira... e não tinha confusão não. Eles vinham, tinha porco, era animado, trabaiavam [...] Os mutirão era muito animado. Eu era bem nova nessa época, eu alembro que cada um de nós que ia, levava o que tivesse. Quem não tinha comida, levava farinha, levava bacaba. A gente ia, trabaiava, comia, comia, e sobrava comida e a gente vinha cheia, mas também a gente trabaiava [...]. (Entrevista 2)

Percebe-se a tradução do trabalho como "brincadeira", animado, festivo, colaborativo, companheiro, que não se materializa nos pimentais, pois lá o trabalho é operado em outro ritmo, isto é, no relógio. Não há espaço, embora haja coletivos, para o lazer que se opera nos mutirões. O momento da alimentação é suprimido pelo tempo da produção. Comem, mas não apreciam, não degustam, não "brincam". O trabalho nos mutirões é pesado, é cansativo, mas é livre, é festivo, assim não é enfadonho como o "trabalho pro outro".

Nos mutirões, no dizer da "mulherada", há a divisão do trabalho. Para a quilombola M.D.C.C. (21 anos, entrevista 7), o trabalho da cozinha é bem atrativo, assim ela nos disse: "eu gosto de ficar na cozinha, fazendo a comida com as outras pro mutirão"; e continua a descrever a divisão dos trabalhos no mutirão entre mulheres e homens dizendo:

Pra fazer o mutirão, os adultos saem convidando, mais os da família né? Eles saem, convidam as famílias, aí a gente vai pra roça. Os adultos cortam a maniva e vão cavando; e a gente vai só colocando a maniva e fechando o buraco. Aí tem a divisão do trabalho: um corta, outros vão plantando. Os homens cortam a maniva e cavam o buraco e as mulheres vão jogando e fechando o buraco. Quando a gente chega no roçado tem o café, depois tem a merenda e aí, quando termina todo o trabalho, tem o almoço, todos juntos [...] Eu não lembro da brincadeira do banguê no convidado, eu só ouço minha mãe dizer que era assim, mas eu nunca vi o convidado com banguê não. Hoje não tem banguê no convidado [...]. (Entrevista 7)

A jovem quilombola M.D.C.C. (Entrevista 7), em seus vinte e um anos de vida, nos revela como os jovens da Comunidade Quilombola Tambaí-Açu vêm (re)construindo junto com os mais velhos (pai, mãe, tios, tias, avós) o mutirão e, em 
contradição ao trabalho dos patrões, suas identidades. A jovem quilombola M.D.C.C. (Entrevista 7) demonstra sua apropriação do trabalho nos mutirões, pois participa com sua família, desde criança na (re)construção deste.

O mutirão, como experiência herdada e modificada (THOMPSON, 1998), é base da constituição e manutenção da produção da vida na Comunidade Quilombola Tambaí-Açu e se configura como resistência econômico-cultural ao "trabalho pro outro" nos pimentais, pois mantém vivo o trabalho da roça, bem como a subsistência e os valores como de unir forças para ajudar um ao outro.

A divisão do trabalho entre homens e mulheres, observada pela jovem quilombola M.D.C.C. (Entrevista 7) nos mutirões da Comunidade Quilombola Tambaí-Açu, nos dias atuais, também foi observada por Pinto (2004, p. 102), durante suas pesquisas em comunidades tradicionais quilombolas da região do Baixo Tocantins, nordeste paraense, assim:

Ao som do sopro de uma corneta, que marcava o momento esperado para o plantio, os homens com as enxadas na mão se espalhavam pelo roçado formando eitos - espécie de alinhamento - e agilmente removiam a terra formando covas. Atrás dos cavadores iam as mulheres, velhos e crianças, com paneiros cheios de mudas, depositando de uma a duas mudas em cada cova e simultaneamente cobrindo-a com a terra - geralmente a terra é puxada com os pés.

Percebe-se com isso que, nos mutirões quilombolas, o trabalho é dividido entre trabalho mais "leve" para as mulheres e crianças e trabalho mais "pesado" para os homens. Há preocupação dos homens ao designarem os trabalhos "leves" às mulheres, como relação de companheirismo, pois não se percebe nos sujeitos que, ao designarem trabalho leve e trabalho pesado, façam isso por se sentirem superiores, mas como ato de cuidar do outro. Isso é diferente da lógica dos pimentais, onde também se opera esta divisão, pois lá as mulheres, no dizer do quilombola J. C. N. (75 anos, entrevista 5), são vistas como muito "boas para a colheita, elas colhem mais que os homens", colheita aqui como forma de maior produção, lucro de mercado.

Nas roças da comunidade, isso também acontece. A capina e a colheita são direcionadas às mulheres, pois, como nos disse o quilombola R. S. N. (44 anos, entrevista 4), "é um trabalho que elas dão conta". Os homens fazem a parte mais 
"pesada" do roçado, não que elas (mulheres) não consigam fazer, pois, na ausência dos homens, as mulheres já fizeram e fazem mutirões para se ajudarem diante da múltipla jornada de trabalho, em cuidar da roça, da casa, da família, da comunidade, etc. A diferença, contudo, está no valor de uso que isso representa para a comunidade, em oposição ao valor de troca, mercadoria, produção mercantilizada, que assume no trabalho dos pimentais.

Dessa forma, foi observado o reconhecimento de todos os homens entrevistados no sentido de perceberem que não foi e não é fácil o trabalho da "mulherada", tanto nas atividades produtivas da roça quanto de outros trabalhos. A divisão das mulheres entre vários trabalhos na lida diária, em uma dinâmica de trabalho múltiplo - roças, casa, cuidar das crianças -, foi importante para a resistência dos mutirões na saída de alguns homens ao "trabalho pro outro". A persistência das mulheres no trabalho da roça, com vistas à sobrevivência dos filhos, foi crucial para a manutenção da comunidade.

Assim, o reconhecimento de A. N. C. (65 anos, entrevista 6), ao afirmar que "se elas precisar, elas consegue", pois se unem em mutirão quando percebem que, sozinhas, não vão conseguir realizar todas as tarefas a elas direcionadas, demonstra que as mulheres da Comunidade Quilombola Tambaí-Açu foram e ainda são cruciais em assegurar a produção da vida nessa comunidade.

A divisão do trabalho entre mulheres e homens, no mutirão, também foi observada em termos do formato das "brincadeiras" relacionadas à festividade do convidado, pois as mulheres, no dizer dos homens, são "fracas" para algumas "bebidas", já que:

Nós se organizava, né? Assim, naquela época, do que a gente chama convidado, né? Pra gente tocar o serviço da gente, a gente fazia aqueles convidado pra tocar o serviço da gente, como roçage. E aí vinha a planta, fazia aquelas plantas, aqueles cunvidado animado, matando porco. Com aqueles cunvidado grande e, naquela época tinha muita bebida, né?, eu lembro que a gente fazia aqueles licor de muruci, de jenipapo... fazia aquele licor pra dar pra aquelas mulheradas que são mais fracas, a gente fala né? E aí pra ser animado o serviço da planta sabe? As mulheradas entravam animadas e homens também com licor, a bebida mais forte pra fazer o trabalho. E assim a gente tocava o serviço. (Entrevista 6).

Os dizeres e fazeres dos homens da Comunidade Quilombola Tambaí-Açu revelam um "certo" cuidado com as mulheres, pois a elas designam os trabalhos 
mais "leves". Alguns homens da Comunidade Quilombola Tambaí-Açu, antes de irem trabalhar nos pimentais, faziam os mutirões com as mulheres, na derrubada da mata, na cuivara e até no plantio. Passadas essas etapas, dirigiam-se aos pimentais e as mulheres encaminhavam o restante da produção da roça; juntas, uniam-se e faziam mutirões femininos.

Nesse contexto, o quilombola A.N.C. (Entrevista 6) nos revelou o seu reconhecimento de que as "mulheradas" foram responsáveis por "segurar" os mutirões, ou seja, a comunidade, enquanto estavam dedicados aos trabalhos dos patrões dos pimentais, pois,

[...] as que não foram, não quiseram ir pros pimentais, elas continuou com o mutirão, porque essa minha mulher aqui, elas trabalhavam né? Elas se reuniam aí umas oito, nove, dez mulherada. Aí nas roças dela ... e elas falaram - olha bora trabalhar no mutirão e nas nossa roça. E elas iam, naquela animação. Hoje se trabalhava pra uma, outro dia pra outra e assim elas iam acabando com o que tinha de trabalho na roça. Assim, uma ajudando a outra. Se era pra ficar uma semana e pouco trabalhando aqui, e aí direto só num dia eles acabavam, porque, numa semana, eram seis dias pra trabalhar só ela, só uma, e aí elas entravam de nove a dez mulheres e só num dia elas terminavam. Então era uma vantagem. Então o nosso ficava pronto e aí já ia aprontar a de outra, e assim ia, amanhã é de um, depois de amanhã outro e assim ia. Elas, mulherada, se reuniam pra ajudar uma as outras, porque alguns de seus maridos estavam nos pimentais. Outros estavam em outros afazeres e aí elas ficavam sozinha. E se viram que no mutirão elas se ajudavam mais. E assim fizeram. E aí a capina da roça ficava pra mulherada. E aqui se tinha um dizer que sempre a capina da roça era a mulher que fazia. Mas a gente tinha o entendimento que não era só pra mulher, o homem também, se quisesse fazer, também podia fazer, ajudar, quer dizer o homem também faz né?

O relato do quilombola A. N. C. (Entrevista 6) nos apresenta sua experiência com o trabalho das "mulheradas", que foram e são fundamentais no (re)criar-se do mutirão. O papel das mulheres em manter o mutirão, enquanto os maridos trabalhavam "pro outro", foi crucial para que a comunidade não morresse. Ao ficarem, demonstraram que o trabalho da comunidade é o que dignifica, é o que dá subsistência e valores como a união que manteve e ainda mantém a comunidade, provando, todos os dias, a real possibilidade de outras vivências humanas e solidárias.

O cotidiano das mulheres quilombolas se revela com mediações contraditórias nas relações de gênero, da mesma maneira que evidenciam a diversidade da divisão de papéis por sexo, desconstruindo, em muitos casos, a normatividade predominante em nossa sociedade. As tarefas executadas, embora 
por vezes em nome do "companheirismo" de alguns homens, ao tentar designar os "trabalhos leves" dos "trabalhos pesados", não são pré-determinadas, nem impositivas e, em muitos casos, observa-se até uma inversão de papéis masculinos e femininos, como já observado por Costa (2017) em suas reflexões sobre protagonismo de mulheres negras, como também atestam as pesquisas de Pinto (2004), para a qual:

Desmonta-se, dessa forma, o discurso de predomínio masculino cuja delimitação principal se constitui pela distinção de funções entre sexos. Desse modo os papéis informais, improvisados, tem um sentido importante na desmistificação do tão discutido sistema patriarcal brasileiro. Por tradição e costume, a divisão de função entre os sexos era rigidamente a parte e bem demarcada, estabelecendo-se esferas de atuação completamente e nitidamente separadas. De fato, a ausência do homem ou sua presença intermitente impunha com frequência não tanto a divisão como alternância ou troca de tarefas (DIAS, 1995). O sobreviver torna-se a principal arma de luta capaz de impulsionar as mulheres negras rurais a praticar papéis, ora considerados de homens, como até mesmo chefiar a família. (PINTO, 2004, p. 140).

Neste sentido, na relação entre mulheres e homens-negros, durante o escravismo, também observou Davis (2016) que a divisão do trabalho doméstico não era hierárquica; os homens não eram superiores nem inferiores ao trabalho realizado pelas mulheres. Ambos se percebem como igualmente necessários. Além disso, a divisão entre os sexos nem sempre foi rigorosa; às vezes os homens trabalhavam em casa e as mulheres podiam cultivar a roça, pescar, ou até mesmo participar da caça. No que concerne à divisão do trabalho, Pinto (2004, p. 130) nos faz pensar que:

A mulher rural (quilombola) ao se entregar aos trabalhos da roça garante a subsistência e em consequência disso sobrevive e luta pela sobrevivência de seus descendentes. Ela é uma artista da vida porque em meio a todos os sacrifícios e sofrimentos da vida dura de trabalho que vive faz de seu cotidiano uma escola de onde acumula saberes consagrados na sua experiência de vida. As trabalhadoras rurais são mulheres "camaradas" e companheiras dos homens - como eles e elas mesmas dizem [...].

Nos Quilombos, conforme nos revelou Pinto (2004), os homens reconhecem a importância das mulheres na produção do trabalho, pois, para eles, 
elas foram e são "companheiras". Entretanto, é válido ressaltar, conforme Pinto (2004, p. 137), que:

O momento do sobreviver é o momento do poder. É no âmbito da luta pela sobrevivência que se evaporam a "fragilidade" e a "dependência" das mulheradas negras rurais na região do Tocantins/Pará, [...] Mulheres sofridas, calejadas, envelhecidas pela dureza da vida e ressecadas pelo sol escaldante do dia-a-dia cortam com machado, encoivam, plantam, capinam e colhem. A elas estão designadas as tarefas ditas mais "leves" dos trabalhos da roça. Mas a elas também cabe $o$ ato de gerar, parir, cuidar e alimentar os filhos. Atividades que se acumulam ultrapassando as barreiras da noção de "leves", ganhando uma densa complexidade, mas possível para essas mulheres, que na labuta do cotidiano na luta pela sobrevivência tornam-se fortes, independentes e detentoras de poderes.

A jornada exaustiva das mulheres, embora reconhecida por alguns homens, ainda é um campo de debate, pois ainda prevalece o elemento patriarcal, em termos de trabalho-cultura. Contudo, as mulheres da Comunidade Quilombola Tambaí-Açu sempre procuraram ocupar seus espaços, na cura, na sabedoria das ervas medicinais, nos partos caseiros, em casa, na(s) Igreja(s), na Escola formal, na Associação, na organização dos mutirões, no Grupo de Mulheres "Filhas da Resistência"; ou seja, embora os homens procurem estar sempre à frente, enquanto lideranças na comunidade, as mulheres também vêm (re)construindo seus espaços e se dividem entre as tarefas das roças, das famílias, da comunidade. As atividades laborativas voltadas às mulheres rurais são, conforme Thompson (1998, p. 287), "os trabalhos mais árduos e prolongados de todos".

No recriar de suas práticas, as mulheres e os homens da Comunidade Quilombola Tambaí-Açu se (re)constroem, se autoformam. No processo de (re)afirmação quilombola, o ser quilombola mulher também se (re)afirma e os homens também se (re)criam, se formam, daí a necessidade da educação, nos espaços (escolas) da família, dos movimentos sociais, nas escolas formais, nas igrejas, nos mutirões, nos coletivos de mulheres, nos grupos culturais, a exemplo do "Quilombauê5"; enfim, em todos espaços-tempos do fazer-se humano, pois

\footnotetext{
${ }^{5}$ Trata-se de um Grupo cultural da Comunidade Quilombola Tambaí-Açu, em que, com instrumentos produzidos por si mesmos, através de seus saberes, tocam e dançam músicas como samba-de-cacete e banguê, ritmos de ancestralidade africana.
} 
[...] as mulheres do campo além de lidarem, historicamente, com desigualdade de gênero, discriminação e exclusão social, tem o seu bem viver desafiado, cotidianamente, pelo agronegócio, pela degradação da natureza e pela sedução de seus filhos pelo trabalho assalariado. (NEVES, 2017, p. 261 apud CAETANO; RAMOS; AZEVEDO, 2018, p. 185).

De tal modo, não se pode perder de vista que o sociometabolismo do Capital (MÉSZÁROS, 2011) tem tentando transformar as reproduções da vida. As comunidades originárias e tradicionais têm enfrentado uma crise de reprodução social, desencadeada por múltiplos ataques contra suas bases materiais e formas de subsistência, que garantem suas [re] existências. E as mulheres têm sido amplamente afetadas de diversas formas e desigualmente, conforme Trujillo (2020).

Entretanto, em meio ao sistema capital, as mulheres negras-quilombolas, assim como as indígenas, têm mobilizado ações de contraordem, que despontam como ações realmente anticapitalistas, lutas pelo Comum. Assim, na contradição entre as reproduções ampliadas da vida e as reproduções ampliadas do capital, as mulheres e suas identidades se (re)constroem tanto para si quanto para os outros e se formam, já que

[...] O entendimento dessa sociedade (patriarcal-racista-capitalista) exige compreender que as classes sociais não são meras abstrações, mas sim relações sociais que envolvem antagonismos inscritos em uma materialidade de corpos reais, que possuem sexo/sexualidade, raça/etnia. (CISNE, 2018, p. 213).

Nesse sentido, entender as mulheres quilombolas, enquanto gênero e luta, não é sinônimo de fragmentação da classe, mas de inseri-las no campo de debate da hegemonia (GRAMSCI, 1976), pois as lutas das mulheres também são parte dos processos de formação das classes sociais.

Compreendê-las como parte das classes sociais em formação é compreendê-las como parte das heterogenias que compõem a classe trabalhadora em constante formação. Assim, conforme Cisne (2018, p. 213, grifos nossos), a "Unidade exige, todavia, o reconhecimento das diferenças. Do contrário seria homogeneidade, (logo não sendo) homogênea é permeada e constituída pelas relações de sexo e raça".

As mulheres quilombolas são fundamentais em quaisquer processos de organização. Como vimos, suas forças de trabalho têm sido comumente 
importantes para a conservação da sociedade como está. Embora os avanços tenham direcionado a ampliação dos espaços da mulher, estas continuam na luta por romper com a subordinação do homem associado à mulher, que, de uma maneira ou de outra, ainda se manifesta como a própria concepção da propriedade privada (CISNE, 2018, p. 216). Entretanto, luta-se, nesses termos, continuamente para que transformações ocorram não somente no campo econômico, mas também nos campos da cultura e dos valores.

\section{Considerações}

A relação trabalho e processos formativos de mulheres quilombolas, analisada neste artigo, encaminha pensar que as pequenas e grandes lutas formam, pois a individualidade e os processos formativos são necessariamente sociais. Ao se produzir a história, muda-se a realidade e, neste movimento, muda-se também o pensamento e consequentemente os produtos deste pensamento. Logo, na sociedade do Capital, em que tudo converge ao consumo, competição, egoísmo, acabamos por construir também o individualismo (FRIGOT'TO; CIAVATTA; CALDART, 2020), mas que tem, em comunidades tradicionais, como quilombolas, sua oposição, por meio da busca de ações coletivas de cuidado com o outro e com a produção para a vida.

Frente a isso, contudo, havemos de considerar que esse individualismo não é resultante de uma suposta natureza humana sem história, mas fruto de relações firmadas pelo modo de produção capitalista (FRIGOTTO; CIAVATTA; CALDART, 2020), posto que a produção da vida determina a consciência, de maneira que é na luta, na labuta das conjunções sociais contrárias ao Capital, tanto no campo econômico como cultural, que nos constituímos (THOMPSON, 1987).

Neste sentido, as lutas-resistências das mulheres negras rurais - quilombolas - têm sido educativas, já que "a luta concreta também dá-se na e pela [re]construção de relações sociais firmadas na cooperação e solidariedade" (FRIGOTTO; CIAVATTA; CALDART, 2020, p. 14, grifos nossos); ou seja, as mulheres quilombolas resistem e lutam contra o Capital no fazer-se coletivo, na busca pela 
produção da vida, enquanto valor de uso, posto que suas lutas, embora diferentes das lutas de "outros" coletivos femininos, têm se configurado, a seus modos, como luta anticapitalista, pois defendem no cotidiano de suas comunidades o direito a ter direito, à terra, ao trabalho, educação, saúde; enfim, lutam pelo direito de produzir a vida, pelo que lhes és comum, tendo como base os saberes coletivos dos mutirões, que são compreendidos como "necessidade para a comunidade, hoje", como destacou a professora quilombola M.L.R.P (35 anos, entrevista 9), constituindo-se como vozes das mulheres, que os mantêm.

As mulheres quilombolas ao resistirem às ações do Capital, no contexto da Comunidade Quilombola Tambaí-Açu - Mocajuba/PA, Amazônia, através dos mutirões, evidenciam que as mulheres do campo negras-quilombolas lutam e resistem às reproduções ampliadas do capital, no movimento real da vida, econômica e culturalmente. Aos seus modos, configuram "outras" lutas, para além do que se compreende como lutas clássicas ao capital: paralisações de fábrica, piquetes, manifestações, greves. Assim, formam “outros” coletivos femininos.

Nas pequenas lutas cotidianas no campo, tendo a centralidade do trabalho como leme, as relações que se engendram, neste mesmo mundo material, se interseccionam e se fundem com outras lutas; e se tornam grandes lutas, por exemplo, ao produzirem um trabalho que destoa do "trabalho para outro", ou seja, do trabalho para capital, na participação da organização da comunidade, construção de seu protagonismo político ao assumirem lideranças de movimentos sociais, coletivos femininos, dentre outras formas. Nesta construção, produzem a vida, a cultura, a [re]construção de si mesmas. Ao [re]construírem todos os dias suas identidades, enquanto mulher, raça e classe, se formam.

Nota-se também que estas resistências têm sido contraditórias ao capitalismo, pois estão inseridas neste mesmo mundo e atravessadas de diversas formas. Entretanto, observa-se que, ao negarem o "trabalho pro outro" e se [re]construírem nos mutirões mesmo modificados, as mulheres quilombolas resistem ao capital, pois [re]criam o trabalho que destoa do trabalho para o mercado. Logo, sejam elas pequenas ou grandes lutas, que se opõem ao capital, mesmo inseridas nesta materialidade, mostram que é possível [re]construir um mundo, para além do capital. Neste contexto, já há ações em curso que nos demonstram na 
prática a possibilidade de viver bem, isto é, ao contrário de viver melhor como tenta nos impor o capital, ao pressupor que outros vivam pior (ACOSTA, 2016).

As comunidades tradicionais quilombolas e suas mulheres têm nos mostrado, na práxis, a própria cosmologia do "Bem Viver" (ACOSTA, 2016), pois têm em suas ações o contato direto com a natureza e seus diversos saberes, que se contrapõem ao modo capitalista de sociedade, a exemplo dos mutirões quilombolas e sua produção de valores, de cultura do "cuidar do outro". As mulheres quilombolas têm demonstrado seu protagonismo com "outras" formas de luta em oposição ao capital, como observado nas ações de lideranças que assumem na religiosidade, com seus saberes ancestrais, ao serem benz̧endeiras, curandeiras; na ação que assumem enquanto parteiras, respeitadas por todos da comunidade. Ações de fé, por exemplo, que no cristianismo são negadas, excluídas, personificando-se como o próprio capital, ao tentar homogeneizar, até mesmo, os campos simbólicos, enquanto modelo único a ser seguido, pautados no eurocentrismo.

Igualmente, "outras" ações, que destoam do Sistema Capital, têm sido protagonizadas por mulheres quilombolas, ao assumirem também a liderança de Comunidades de Base Cristã, contraditoriamente contribuindo para a organização da comunidade, assim como nas Associações destas comunidades, Sindicatos de Trabalhadores e Trabalhadoras rurais, nos Grupos de mulheres - coletivos femininos, tais como: "Filhas da Resistência" (Quilombo Tambaí-Açu/PA), "Flor da Roça” (Quilombo Icatu/PA), "Divas do Artesanato” (Quilombo Engenho/PA), nas Escolas formais, dentre outros espaços.

Neste sentido, as mulheres quilombolas e suas lutas têm nos ajudado a compreender concretamente o que os movimentos de mulheres negras do mundo inteiro têm procurado demonstrar principalmente nas últimas décadas, ou seja, de que as lutas das mulheres negras e quilombolas têm nos conduzido a uma ampliação dos estudos das sociologias, das filosofias, das epistemologias, dos mais diversos pensamentos, [re]criando, no sentido real, em oposição a uma sociedade e seu sistema autodestrutivo, o capitalismo, ainda hegemônico. No trabalho da vida, as mulheres quilombolas da Amazônia, desde suas ancestrais quilombolas, demonstraram exercerem importantes papéis políticos, econômicos, sociais e culturais (PINTO, 2010). 
Deste modo, vivem para além de abstrações. A necessidade de compreensão da realidade concreta, nos "tempos estranhos" em que vivemos, torna-se cada vez mais necessária. Precisamos romper com "idealismos", por exemplo, que tentam nos moldar enquanto pesquisadoras/es, de que "certos" campos do conhecimento não dão conta de compreender a realidade, isto é, precisamos construir a unidade das lutas sociais. Assim, campos de conhecimento como o Marxista e seus diversos "ismos" podem e devem contribuir, enquanto materialista histórico-dialético, na compreensão da formação da sociedade e suas diversas manifestações de classes sociais, com cores, raças, gêneros... Por que não?

Estudiosas, feministas, marxistas, intelectuais orgânicas como Lélia González, Sueli Carneiro, Angela Davis, Cinzia Arruzza, Tithi Bhattacharya, Nancy Fraser, Mirla Cisne, Heleieth Iara B. Safiotti, dentre outras, apontam que é possível sim "interseccionar" e "fundir ou enovelar" algumas categorias dos estudos marxistas com os estudos feministas negros/quilombolas, como forma de "sul-amefricanizar" os conhecimentos e ações, compreendendo que há unidade no diverso, ou seja, raça-gênero-classe-patriarcado-capitalismo são parte do mesmo novelo - processo histórico-social.

Embora vejam como um grande desafio, pois requer muito rigor de estudo, pesquisa, essas autoras-pesquisadoras nos apresentam que estudar as desigualdades sociais enquanto raça, gênero, classe, patriarcado, assim como outras categorias neste âmbito, numa sociedade de mercado, é inviável sem considerar o campo marxiano de análise, pois é "à teoria marxista que devemos cobrar a fatura (ou fratura) por não ter pensado concomitantemente a instauração das desigualdades e das hierarquias em consórcio com o racismo e o sexismo, impostos pelo capital” (BORGES, 2016, p. 51), ou seja, cabe a nós pesquisadoras/es preencher essas lacunas.

Com isso, para não concluir... continuamos com algumas indagações: Como as mulheres negras-quilombolas têm construído espaços-tempos de lutas, neste mundo do capital, já que, para este sistema, as mulheres, inclusive negras e quilombolas, são meros instrumentos de produção? Os acúmulos de poder construídos pelas mulheres podem ser compreendidos como relações que permeiam a centralidade do trabalho? Podemos considerar as "outras" lutas das mulheres quilombolas descoladas das lutas sociais, que formam classes sociais? Como 
reconhecer, considerar, estudar, as mulheres quilombolas e as questões que lhes oprimem nesta sociedade de mercado, sem considerar as relações de trabalhoeducação?

Assim, ao considerar os processos formativos das pequenas às grandes lutas das mulheres negras quilombolas: o que pensam estas mulheres? O que fazem? Como reagem? Como se organizam? As evidências nos apresentam que são mulheres que lutam, resistem ao capital, mas ainda precisamos investigar, pensar, demonstrar que são parte destes processos de coletivos "femininos" que, a seus modos, também constroem a história.

\section{Referências}

ACOSTA, A. O Bem Viver. Uma oportunidade para imaginar outros mundos. Trad. Tadeu Breda. São Paulo: Autonomia Literária; Elefante, 2016.

ARRUZZA, C.; BHATTACHARYA, T.; FRASER, N. Feminismo para os 99\% - Um manifesto. [livro eletrônico]. São Paulo: Boitempo, 2018.

BARDIN, L. Análise de conteúdo. Lisboa: Edições 70, 1977.

BOGO, A. Identidade e luta de classes. 2. ed. São Paulo: Expressão Popular, 2010.

BORGES, R. Feminismos negros e marxismo: quem deve a quem? Revista da BoitempoMargem Esquerda (Racismo: Dossiê Marxismo e Questão Racial), São Paulo, n. 27, out. 2016.

CAETANO, E.; RAMOS, A. D. O.; AZEVEDO, E. E. F. N. A produção associada em Comunidades e Povos Tradicionais em Mato Grosso: pesquisas e reflexões coletivas do GEPTE/UFMT. Revista Trabalho Necessário: Trabalho e educação em comunidades tradicionais, v. 16, n. 31, p. 165-190, 2018. Disponível em: http://periodicos.uff.br/trabalhonecessario/article/view/27376. Acesso em: 8 set. 2018.

CALDART, R. S. et al. (org.). Dicionário da Educação do Campo. Rio de Janeiro: EPSJV; São Paulo: Expressão Popular, 2012.

CISNE, M. Feminismo e Consciência de Classe no Brasil. São Paulo: Cortez, 2015.

CISNE, M. Feminismo e marxismo: apontamentos teórico-políticos para o enfrentamento das desigualdades sociais. Serviço Social e Sociedade, São Paulo, n. 132, p. 211-230, maio/ago. 2018. DOI: http://dx.doi.org/10.1590/0101-6628.138. Disponível em: http://www.scielo.br/pdf/sssoc/n132/0101-6628-sssoc-132-0211.pdf. Acesso em: 8 set. 2018.

COSTA, J. P. A. Gênero, saberes e poder: O protagonismo de mulheres negras na organização política e social da Comunidade Remanescente de Quilombos São José de Icatu Mocajuba/PA. 164 p. Dissertação (Mestrado em Educação e Cultura) — Programa de PósGraduação em educação e Cultura, Campus Universitário do Tocantins/Cametá, Universidade Federal do Pará, Cametá, PA, 2017. 
DAVIS, A. As mulheres negras na construção de uma utopia. In: I JORNADA CULTURAL LÉLIA GONZÁLEZ, 1., 1977, São Luiz. [Anais...] São Luiz: Centro de Cultura Negra do Maranhão, 1977.

DAVIS, A. Mulheres, Raça e Classe. São Paulo: Boitempo, 2016.

FISCHER, M. C. B.; ZIEBELL, C. R. Mulheres e seus saberes engravidando uma outra economia. In: REUNIÃO ANUAL DA ANPED, 28., 2005. Caxambu, MG. Anais eletrônicos... [S.l.]: Anped, 2005. Disponível em: http://28reuniao.anped.org.br/gt03.htm. Acesso em: 12 mar. 2020.

FONSECA, M. V. Relaçoes étnico-raciais e Educação no Brasil. Rio de Janeiro: Maza, 2011.

FUNES, E. A. Nasci nas matas, nunca tive senhor. História e memória dos mocambos do baixo Amazonas. In: REIS, J.; GOMES, F. S. (org.). Liberdade por um fio: história dos quilombos no Brasil. São Paulo: Claro Enigma, 2012.

FREITAS, D. O escravismo brasileiro. 2. ed. Porto Alegre: Mercado Aberto, 1982.

FRIGOTTO, G. Educação e a Crise do Capitalismo Real. 6. ed. São Paulo: Cortez, 2010.

FRIGOTTO, G.; CIAVATTA, M.; CALDART, R. S. (org.). História, Natureza, Trabalho e Educação/Karl Marx e Friedrich Engels. $1^{\mathrm{a}}$ ed.- São Paulo: Expressão Popular, 2020.

FRIGOTTO, G.; CIAVATTA, M.; RAMOS, M. O trabalbo como princípio educativo no projeto de educaşão integral de trabalhadores - Excertos. 2005. Disponível em: http://redeescoladegoverno.rs.gov.br/upload/1392215839_O\%20TRABALHO\%20COM O $\% 20$ PRINC $\%$ C3\%8DPIO $\% 20$ EDUCATIVO $\% 20$ NO $\% 20$ PROJETO.pdf. Acesso em: 2 out. 2019.

GRAMSCI, A. Americanismo e fordismo. In: GRAMSCI, A. Maquiavel, a politica e o estado moderno. Rio de Janeiro: Civilização Brasileira, 1976.

GENOVESE, E. D. A economia política da escravidão. Rio de Janeiro: Pallas, 1976.

GOMES, F. S. Experiências atlânticas: ensaios e pesquisas sobre a escravidão e o pós-emancipação no Brasil. Passo Fundo, RS: UPF, 2003.

GONZÁLEZ, L. Racismo e sexismo na cultura brasileira. Revista Ciências Sociais Hoje, p. 223-244, 1984.

GONZÁLEZ, L. A categoria político-cultural de amefricanidade. Tempo Brasileiro, Rio de Janeiro, n. 92/93, p. 69-82, jan./jun. 1988.

MARX, K.; ENGELS, F. Manifesto do Partido Comunista. In: BOGO, A. (org.). Teoria da Organização Política. São Paulo: Expressão Popular, 2005.

MÉSZÁROS, I. Para além do capital: rumo a uma teoria da transição. Trad. Paulo Cezar Castanheira, Sérgio Lessa. Campinas, SP: Ed. Unicamp; São Paulo: Boitempo, 2011.

PINTO, B. C. M. Escravidão, fuga e a memória de quilombos na região do Tocantins. São Paulo: PUC-SP, 2001. 
PINTO, B. C. M. Nas Veredas da sobrevivência: memória, gênero e símbolos de poder feminino em povoados amazônicos. Belém: Paka-Tatu, 2004.

PINTO, B. C. M. Memória, oralidade, danças, cantorias e rituais em um povoado amazônico. Cametá, PA: BCMP, 2007.

PINTO, B. C. M. Filhas das matas: práticas e saberes de mulheres quilombolas na Amazônia Tocantina. Belém: Açaí, 2010.

PISTRACK, M. M. Fundamentos da escola do trabalho. Trad. Luiz Carlos de Freitas. São Paulo: Expressão Popular, 2018.

SAFFIOTI, H. Gênero, patriarcado, violência. São Paulo: Fundação Perseu Abramo, 2004.

SALLES, V. O negro no Pará: sob o regime da escravidão. 2. ed. Belém: Secretaria de Estado da Cultura; Fundação Cultural do Pará “Tancredo Neves”, 1988.

THOMPSON, E. P. A formaşão da classe operária inglesa: a árvore da liberdade. 4. ed. São Paulo: Paz e Terra, 1987. v. 1.

THOMPSON, E. P. Costumes em Comum: estudos sobre a cultura popular tradicional. Trad. Rosaura Eichemberg. São Paulo: Companhia das Letras, 1998.

TRIVIÑOS, A. N. S. Introdução às pesquisas em ciências sociais: A pesquisa qualitativa em Educação. São Paulo: Atlas, 1987.

TRUJILLO, M. L. N. Mujeres em lucha por la defesa de la vida asediada y afectada los extractivismos en México. Revista Trabalho Necessário. Lutas no Campo e o Comum na América Latina, Niterói, v. 18, n. 36. p. 118-142, 2020.

RECEBIDO: $31 / 08 / 2020$

APROVADO: 05/10/2020

RECEIVED: 08/01/2020

APPROVED: $10 / 05 / 2020$

RECIBIDO: $31 / 08 / 2020$

APROBADO: 05/10/2020 